Article

\title{
Principles of Affective Design in Consumers' Response to Sustainability Design Strategies
}

\author{
Maria-Jesus Agost (D) and Margarita Vergara * (iD \\ Departament d'Enginyeria Mecànica i Construcció, Universitat Jaume I, 12071 Castelló de la Plana, Spain; \\ magost@uji.es \\ * Correspondence: vergara@uji.es
}

Received: 27 November 2020; Accepted: 16 December 2020; Published: 17 December 2020

\begin{abstract}
The aim of this paper is to explore the generation of consumers' responses to sustainability design strategies by considering the principles of affective design. A conceptual model of consumers' response, in which a distinction is made between subjective impressions and behavioral responses, is defined and validated by conducting an experiment. Six wardrobes, representing sustainability design strategies (refurbishment, adaptability, durability, personalization, maintenance and flexibility) were selected. Eighty-seven participants assessed 14 impressions of the wardrobes including long-life, functional, aesthetic, emotional and environmental aspects as well as behavioral responses (product attachment and willingness to keep). Long-life impressions are more related to willingness to keep, while aesthetic ones are more closely linked to attachment. Practical and emotional impressions are associated with both behavioral responses. Design strategies and personal concerns have an influence on consumer response. These results are expected to help managers and designers promote a sustainable behavior by selecting the most suitable design strategies.
\end{abstract}

Keywords: affective design; consumer response; sustainability; product attachment; willingness to keep

\section{Introduction}

In the field of affective design, it is well known that product design has a communicative function [13]. In this communication between the individual and the product, the product design elicits different cognitive (meanings) and affective responses (emotions) of different types and intensities [1,4-6], hereafter called subjective impressions. These subjective impressions give rise to a global assessment of the product [2], product preferences [7] and behavioral responses [1,8]. Therefore, human factors in product design can be used to fulfill users' needs and wants [9].

Personal criteria such as sociological reference values or personality traits, resulting from previous experiences, culture, training, and internal and learned rules can also influence consumers' assessment and behavior [2,7]. Consequently, these 'concerns' should be considered a possible influence on subjective impressions and product preferences [10,11]. All these principles of affective design (subjective impressions, product preferences and behavioral responses), together with personal concerns, can be applied to the environmental and sustainability field.

In recent years, environmental awareness has increased among consumers, who are becoming more and more mindful of the consequences that their actions and purchasing decisions have on the environment [12]. When selecting certain products, aware consumers apply criteria that go beyond functionality or aesthetics and are more closely related to ensuring a lower impact on the environment.

Some studies have analyzed how a trade-off between sustainability and functionality affects consumers' choices, with different conclusions: socially responsible consumers promote environmental changes, as their choices can influence the way that products are designed and manufactured $[13,14]$. 
However, products with a superior functional performance are preferred to those with perceived superior sustainability characteristics [15]. Some attempts have been made to relate emotions elicited with environmental attitudes and purchase intention in an affective study of green labels, including visual attention [16], and to relate sustainable design strategies in packaging with behavior, purchase intention, willingness to pay and consumer attitudes $[17,18]$. However, these studies do not consider jointly all of the affective factors influencing these relationships.

Beyond eco-labeling and packaging, and their relationship with the purchase intention, principles of affective design can be applied to the earliest stages to promote and benefit sustainable design [19] in a wide variety of products, knowing that affect is a potential motivation for consumers to engage in sustainable behavior [20]. Thus, designers and managers can reduce the environmental impact of their products by understanding consumers' behavior and orienting them towards more sustainable practices [21-23].

One sustainable paradigm currently considered in product design [24] focuses on development for longevity [25], encouraging the design of long-life products (by ensuring a long period of product usage) and product life extension (by extending the time that goods can be used through maintenance, repair, etc.). In this context, Chapman [8] stated that long-life product design is supported by design for attachment and trust (i.e., emotional durability), while van Nes and Cramer [26] established five design strategies for influencing product lifetime and the replacement decision, namely: design for reliability and robustness, repair and maintenance, upgradability, product attachment and variability. Bocken et al. [27] differentiated among several circular product design strategies, including: (1) Design for long-life products (i.e., Design for attachment and trust, Design for durability, and Design for reliability) and (2) Design for product life extension (Design for maintenance and repair, Design for upgradability, Design for standardization and compatibility and Design for dis- and reassembly).

Positive emotions can be used to engender environmentally responsible behaviors $[28,29]$ and, therefore, affective design might be useful in understanding people's motivations to adopt the use of sustainable products and continue to use them [19], and in promoting long-term product involvement. According to affective principles, most of the design strategies presented above are linked to subjective impressions as meanings associated to the product itself (such as robustness or reliability) or emotions elicited in the user (such as trust). However, although product attachment is used repeatedly as a key strategy for long life, it corresponds to a consumer response (a feeling). When people feel attached to an object, they are more likely to handle the product with care and make efforts to keep it in good condition, which results in a longer period of usage [30,31]. Therefore, product attachment (related to willingness to keep and take care of it) should be considered as an affective behavioral response of consumers, unlike the treatment given to product attachment as a design strategy in van Nes and Cramer [26] or Bocken et al. [27]. In view of the abovementioned elements in this interaction, a conceptual model establishing the relationships among the subjective impressions elicited and consumers' behavioral responses, sustainable design strategies and consumer concerns is proposed in Figure 1, based on $[1,2,7]$. 


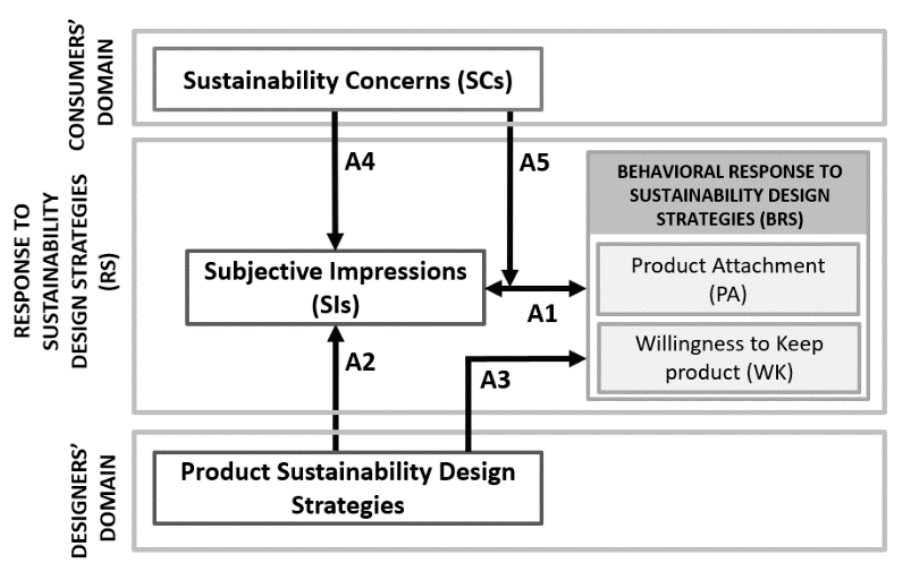

Figure 1. Conceptual model.

Within the response to sustainability design strategies (RS), subjective impressions (SIs) refer to meanings given to the product and the emotions or feelings experienced by the consumer. SIs related to sustainability aspects are, for example, the consumers' perception that a product is eco-friendly (meaning) or that they are being more respectful to the environment while using it (emotion/feeling). The behavioral response refers to the final consumer's behavior, which can be to approach (e.g., buying) or to avoid the product. From a sustainability point of view, the behavioral response to sustainability design strategies (BRS) should include consumers' responses that are more related to sustainability aspects, such as product attachment (PA) and willingness to keep and take care of it (WK). PA is considered to be the degree to which the individual feels attached to the product, usually due to affective and subjective reasons, and denotes preference. PA can lead to WK, which is more related to an action than to a feeling.

Therefore, in reference to the consumers' response, the conceptual model in Figure 1 distinguishes between subjective impressions and behavioral response, so it is possible to delve a little deeper into the relationship between the two components (A1). For the same subjective impression, consumers' behavioral response may be different, depending on their concerns (A5). Thus, for example, if a product is perceived as expensive-looking, some luxury-seeking consumers may feel attracted to it, while others may consider the product too ostentatious and reject it. Hence, sustainability concerns (SCs), i.e., the degree to which consumers are concerned with sustainability aspects, such as their trust in sustainable and organic products, are also considered to be an influencing factor. Concerns may also directly influence the generation of subjective impressions (A4). For example, a person with environmental concerns may perceive a backpack made from recycled plastic bottles as respectful and nice-looking, while someone without these concerns might consider it extravagant. Therefore, it is possible to distinguish between the influence of personal concerns on the generation of subjective impressions (A4), and on the relationship between those and the behavioral response (A5). From the designers' domain, sustainability design strategies (design for long-life products and product life extension) influence the subjective impressions elicited (A1). Due to the relationship between these subjective impressions and the behavioral response (A2), sustainability design strategies are also expected to influence consumers' behavioral response (A3).

Some isolated relations among the elements in the model have already been analyzed, as the influence of some sustainability design strategies on certain factors of consumers' response, such as users' emotions, attitudes, consumer behavior or decision making [8,26,27,32-36]. Some of the influences of consumers' sustainability values and concerns on their response have also been studied [37-39]. However, in some cases no distinction is drawn between types of response, and the mediating effect of subjective impressions on the final behavioral response is not considered, so these studies do not fully consider the relationships in the model. 
The use of affect as a driver to behavior towards sustainability has not been given much attention in literature [20]. To the best of our knowledge, no study has focused on exploring, as a whole, all the affective relationships among all the factors at play in the interaction between the consumer and a sustainable product design. This is the first attempt at showing the relationship of design strategies for sustainability, emotions and environmental attitudes, within a thoroughly model in the affective domain.

In an attempt to fill this gap, this paper uses a conceptual model based on the principles of affective design (Figure 1) that allows us to analyze the relationships between design strategies for sustainability and the customers' response by explicitly considering the mediating effects of subjective impressions (A3 as A2 + A1) and sustainability concerns of customers (A5). The aim of this paper is to explore these relationships in greater depth, in order to gain some insights into the influence of sustainability design strategies on consumers' response, based on their personal concerns. As a final goal, it is expected that this information will allow designers and managers to improve the strategic characterization and positioning of their products, based on their target consumers, to achieve product life extension.

Section 2 shows the case study developed in order to collect data of all the elements in the model. Section 3 shows the statistical analyses performed to evidence all the relationships in the model. The results of the study are reported and discussed afterwards in Sections 4 and 5, respectively.

\section{Materials and Methods}

An online questionnaire was designed showing six versions of a wardrobe, linked to six different sustainability design strategies. The participants answered questions about some SCs and assessed the wardrobe versions on different SIs, PA and WK, all using 5-point Likert scales.

\subsection{Selection of Stimuli}

Six design strategies for longer lasting products and for influencing the replacement decision were selected, based on previous works [26,27], whose proposed design strategies were adapted, these being: High durability, Easy maintenance, Adaptable to new functions, Flexible design, Personalized and Refurbished.

Some strategies, like Easy maintenance or High durability, were adopted directly, as proposals from the literature also considered them. In other cases (Adaptable to new functions, Flexible design), the strategies chosen were based on similar strategies from the literature, although the original names have been changed. Each of them gathers two strategies from those proposed by Bocken et al. [27]. In addition, two new strategies have been added to those from the bibliographical sources. Product attachment was included by both proposals as, in the literature, it is considered a design strategy. However, it has been identified in this work as a consumer response. Van Nes and Cramer [26] stated that it links with products that carry memories, are unique or have some personal elements, and they raise the question as to whether the challenge of cultivating product attachment is possible by designing mass products that allow for personalization. Consequently, a personalized strategy has been considered in this work instead.

Furthermore, the strategy of Refurbishment has also been added, as it can influence the consumers' response. Refurbishment is a process that allows a used product to be returned to a good working condition by repairing or replacing damaged components and updating its appearance, if necessary [40].

These six chosen design strategies can be classified in accordance with Carey et al. [9], depending on what the product conveys in terms of utility (High durability and Easy maintenance are strategies based on achieving product utility for a longer time), usability (Adaptable to new functions and Flexible design follow strategies for enhancing product usability over time) and desirability (the Personalized and Refurbished versions target aspirational desires). This classification is also similar to Jordan's levels on the pyramid of needs that products satisfy [41]. In this case, however, the levels do not maintain a hierarchical relationship, but are only considered as types of strategies for long-life products and product life extension. 
The product chosen for the study was a wardrobe, so six versions were generated and presented to the participants with detailed descriptions (see Table 1 and Figure 2).

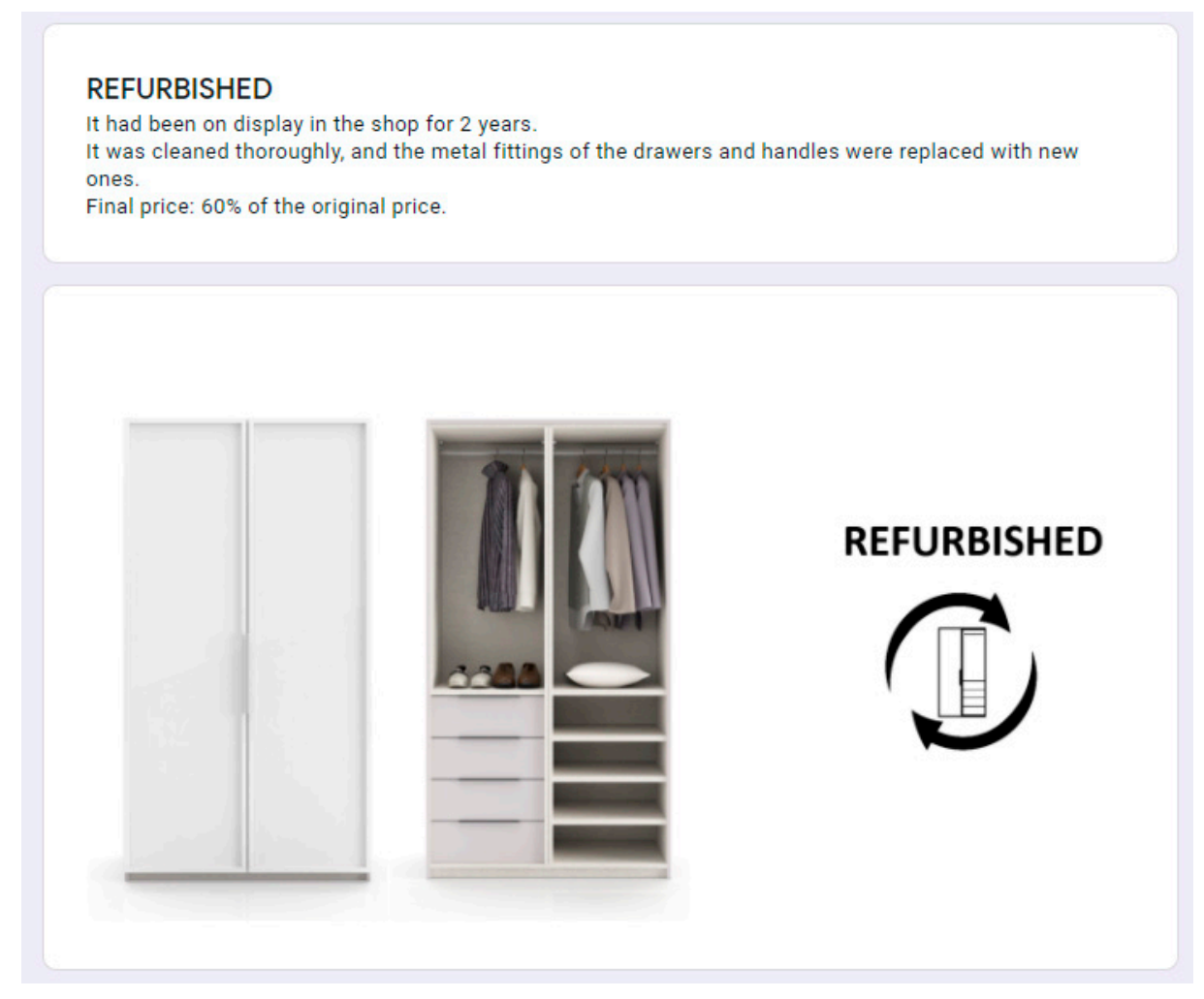

Figure 2. Description of one version of the wardrobe. Partial view of the online questionnaire. Original in Spanish.

Table 1. The detailed descriptions for each design strategy included in the study (translated from the Spanish version that was used).

\begin{tabular}{cl}
\hline Design Strategy & \multicolumn{1}{c}{ Description Used } \\
\hline Refurbished & $\begin{array}{l}\text { It had been on display in the shop for two years. It was cleaned thoroughly, } \\
\text { and the metal fittings of the drawers and handles were replaced with new } \\
\text { ones. Final price: } 60 \% \text { of the original price. }\end{array}$ \\
\hline Adaptable to new functions & $\begin{array}{l}\text { The consumer can, at any time, buy new modules that serve different } \\
\text { purposes (desk, ironing board, bed). The wardrobe can be considered } \\
\text { 'convertible or evolutionary', since it can be adapted to different uses, } \\
\text { depending on the needs that may arise. }\end{array}$ \\
\hline High durability & $\begin{array}{l}\text { The material is highly resistant to scratches and breakage. The drawers and } \\
\text { hinges have a service life of } 80,000 \text { cycles (50 years of average use). }\end{array}$ \\
\hline Personalized & $\begin{array}{l}\text { It is possible to choose any color for the doors, or a personalized image can } \\
\text { even be inserted. }\end{array}$ \\
\hline Easy maintenance & $\begin{array}{l}\text { The design allows for very easy cleaning. It includes replacement fittings, } \\
\text { and replacement modules can be purchased: drawers, shelves, doors } \\
\text { (interchangeable and standard spare parts). }\end{array}$ \\
\hline Flexible design & $\begin{array}{l}\text { The door panels are reversible. The interior modules (drawers and shelves) } \\
\text { can be easily rearranged. }\end{array}$ \\
\hline
\end{tabular}




\subsection{Selection of Subjective Impressions, Behavioral Response and Concerns}

To obtain the initial subjective impression universe, 27 meanings, emotions and other expressions related to the chosen design strategies and to products with specific sustainability characteristics were collected from prior research [35-37] and different websites of furniture products [42-44]. The initial list was reduced by grouping terms with similar meanings, or building new statements from the original expressions. Table 2 shows the 14 SIs finally considered in this study.

Table 2. The statements representing the subjective impressions (SIs) considered in the study (translated from the Spanish version that was used).

\begin{tabular}{cl}
\hline Subjective Impressions (SIs) & \multicolumn{1}{c}{ Statements Used for the Assessment } \\
\hline SI1-Easy maintenance & $\begin{array}{l}\text { It is very easy to keep the wardrobe in good condition or, if } \\
\text { necessary, it would be easy to repair it. }\end{array}$ \\
\hline SI2-Expensive-looking & The wardrobe looks expensive. \\
\hline SI3-Environmentally friendly & The wardrobe is respectful towards the environment. \\
\hline SI4-Reliable & The wardrobe is reliable, robust and durable. \\
\hline SI6-Practical & The wardrobe is a high quality product. \\
\hline SI7-Versatile & The wardrobe is practical and functional. \\
\hline SI8-Nice-looking & The wardrobe is versatile. \\
\hline SI9-Hygienic & The wardrobe looks nice. \\
\hline SI10-Replaceable & $\begin{array}{l}\text { The wardrobe is hygienic. } \\
\text { similar). }\end{array}$ \\
\hline SI12-Overall satisfaction & $\begin{array}{l}\text { The wardrobe instills reliability and security. I would feel confident } \\
\text { about buying it. }\end{array}$ \\
\hline SI13-Life-style fitting & $\begin{array}{l}\text { I would be satisfied with owning it. } \\
\text { I identify myself with the wardrobe. It fits my lifestyle, my needs } \\
\text { and my tastes. }\end{array}$ \\
\hline Sustainability & $\begin{array}{l}\text { I would be satisfied with acquiring it, as I would be contributing to } \\
\text { the sustainability of the planet. }\end{array}$ \\
\hline
\end{tabular}

The statements used to assess the behavioral response to sustainability design strategies are shown in Table 3.

Table 3. The statements representing the behavioral response to sustainability design strategies (translated from the Spanish version used).

\begin{tabular}{cl}
$\begin{array}{c}\text { Behavioral Response to Sustainability Design } \\
\text { Strategies (BRS) }\end{array}$ & \multicolumn{1}{c}{ Statements Used for the Assessment } \\
\hline PA-Product Attachment & $\begin{array}{l}\text { If I owned it, I would feel some attachment towards it. } \\
\text { I would be willing to take care of it and keep it for as } \\
\text { long as possible. }\end{array}$ \\
\hline WK-Willingness to keep & \begin{tabular}{l} 
low \\
\hline
\end{tabular}
\end{tabular}

The sustainability concerns of consumers used for the study (Table 4) were selected from literature classifying personal concerns related to aspects of sustainability [45-48]. The initial number of statements was reduced by combining those with similar meanings. 
Table 4. The statements representing the sustainability concerns (SCs) (translated from the Spanish version used).

\begin{tabular}{cl}
\hline Sustainability Concerns (SCs) & \multicolumn{1}{c}{ Statements Used for the Assessment } \\
\hline SC1-Environmentally respectful & $\begin{array}{l}\text { I try to respect the environment by doing things like recycling or } \\
\text { choosing sustainable products in my purchases. }\end{array}$ \\
\hline SC2-Sustainability trusting & I trust sustainable and organic products. \\
\hline SC3—Practical and responsible & I consider myself a practical and responsible person. \\
\hline SC4-Used to quality & $\begin{array}{l}\text { I am used to buying high quality products, and I don't mind } \\
\text { paying more for them. }\end{array}$ \\
\hline SC5-Willing to refurbish & I would buy refurbished products. \\
\hline SC6-Likes to repair & I like to maintain and repair my belongings. \\
\hline SC7-Product keeper & $\begin{array}{l}\text { Some products are special to me, and I like to keep them for a } \\
\text { long time. }\end{array}$ \\
\hline
\end{tabular}

\subsection{Development of the Study}

An online questionnaire was developed and implemented (in Spanish) to develop a cross-sectional study. The questionnaire was distributed via e mail to adults recruited at random from students and workers at the university. The aim was obtaining a minimum of 80 responses, from different ages, and gender balanced, with different professional profiles. As no reward for answering the questionnaire was offered, two rounds of distributions were needed, to widen the number of responses. Finally, it was sent to more than 120 people and answered completely by 87 (some participants attempted to do the questionnaire without finishing it or reported some problems while answering, and have not been included).

First, an explanation of each version of the wardrobe was presented, as in the example shown in Figure 2. Once the six versions had been presented, they were assessed on the 14 SIs and the BRS (PA and WK), by means of a 5-point Likert scale (example in Figure 3). Each question was shown on a different page, so the image with the six versions (Figure 3) was always visible. Both the order of the questions and the wardrobe versions were randomly distributed among the participants. Finally, questions about SCs were assessed by participants (Figure 4). 


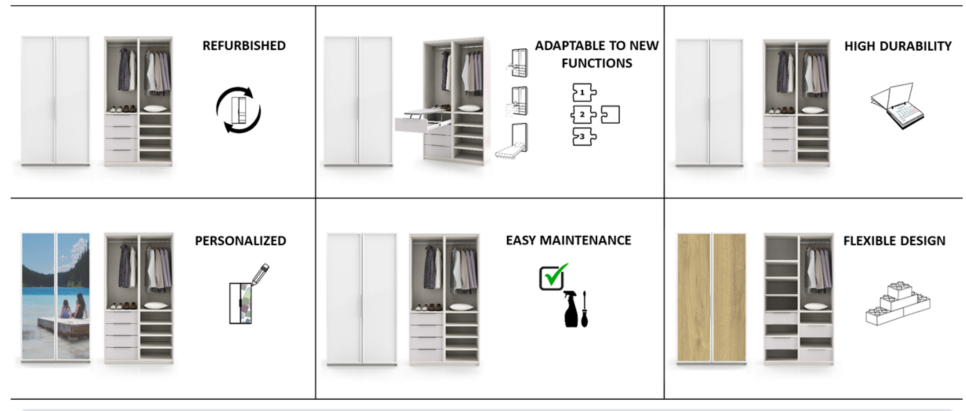

It is very easy to keep the wardrobe in good condition, or, if necessary, it would be easy to repair it.

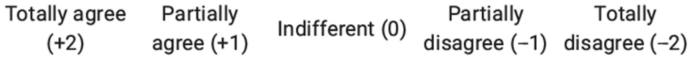

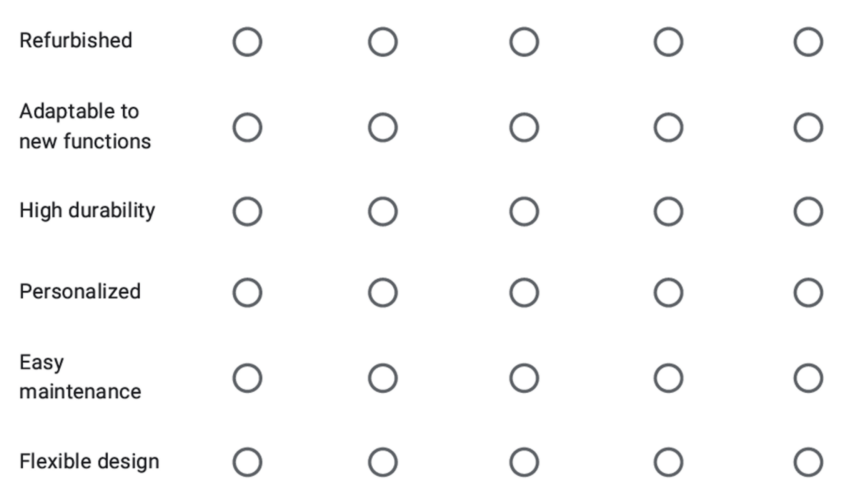

Figure 3. Example of a Likert scale for the assessment of the SIs. Original in Spanish.

\section{CONCERNS}

Finally, please assess the next statements, according to your personal concerns.

I try to respect the environment, by doing things like recycling or choosing sustainable products in my purchases.

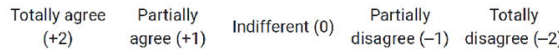

option

$\square \quad \square \quad \square$

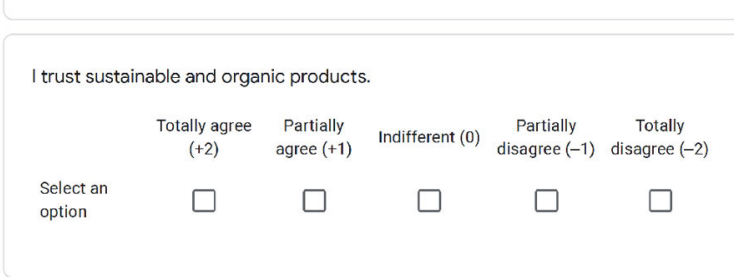

I consider myself a practical and responsible person.

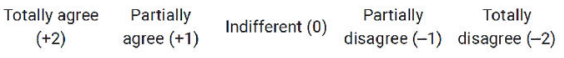

Select an

option

Figure 4. Example of a Likert scale for the assessment of the SCs. 


\section{Analysis of Results}

All of the statistical analyses were performed with the SPSS statistical software (IBM SPSS Statistics 23 for Windows, IBM Corporation, New York, NY, USA).

First, the relationship between the SIs and the BRS (PA and WK) (A1 in Figure 1) was analyzed applying correlations. Spearman's rho correlation coefficient was used, as the normality of variables assumption is violated.

Next, differences in the assessments in SIs and the BRS between the six design versions were analyzed (relationships A2 and A3). To verify the influence of the sustainability design strategies on the assessment of the SIs and the BRS, 16 analyses of variance (ANOVAs) were performed. The ratings for the 14 SIs, together with PA and WK, were considered as dependent variables, and the wardrobe version was taken as the independent one. Games-Howell post-hoc comparisons were applied for Levene critical levels lower than 0.05. Otherwise, Bonferroni post-hoc comparisons were used.

To analyze the influence of the SCs on the assessment of the SIs (A4 in Figure 1), ANOVAs were also applied. However, as the SCs were not selected and collected as factors for the experiment, dummy variables (DSCs) were generated from the ratings of SCs to distinguish two groups in each SC. The DSCs adopted a value of 1 when the rating of the original SCs was a positive number (1 or 2), and 0 otherwise. For the ANOVAs, the ratings for the SIs were considered dependent variables, and the DSC was taken as the independent one.

In order to determine the influence of SCs on the relationship between SIs and the BRS (A5), partial correlations were applied between SIs and PA, and between SIs and WK, controlling for the effect of the SCs. Partial correlations determine the lineal relation between two variables, removing the possible effect of a third variable.

\section{Results}

The questionnaire was answered by 87 participants ( $52.9 \%$ women, age: $23 \%$ under $25,51.7 \%$ between 26 and $45,23 \%$ from 46 to 65 , and $2.3 \%$ aged over 65 ).

Table 5 presents bivariate correlations between the SIs and the BRS (relationship A1 in Figure 1). All the SIs presented a significant positive correlation with PA except for SI1 and SI4 (which presented no significant correlation), and SI10 (which maintained a significant negative correlation). The subjective impressions that were most correlated with PA were aesthetic impressions (SI8 Nice-looking; S2 Expensive-looking) and emotions (SI12 Overall satisfaction; SI13 Lifestyle fitting; SI11 Trust). The weakest correlations (lower values of the coefficients) were found with the SIs linked to the environment and sustainability (SI3 Environmentally friendly; SI14 Sustainability). No significant correlation was detected with the impressions SI1 Easy maintenance and SI4 Reliable, both related to achieving a long use of the product. 
Table 5. The statements representing the subjective impressions considered in the study (translated from the Spanish version that was used).

\begin{tabular}{ccccc}
\hline & \multicolumn{2}{c}{ Attachment (PA) } & \multicolumn{2}{c}{ Willingness to Keep (WK) } \\
\cline { 2 - 5 } & Correlation & $p$ Value & Correlation & $p$ Value \\
\hline SI1-Easy maintenance & $0.008^{* *}$ & 0.862 & $0.241^{* *}$ & 0.000 \\
SI2-Expensive-looking & $0.276^{* *}$ & 0.000 & $0.089^{*}$ & 0.043 \\
SI3-Environmentally friendly & $0.144^{* *}$ & 0.001 & 0.030 & 0.500 \\
SI4-Reliable & $0.081^{* * *}$ & 0.066 & $0.305^{* *}$ & 0.000 \\
SI5-Quality & $0.227^{* *}$ & 0.000 & $0.291^{* *}$ & 0.000 \\
SI6-Practical & $0.188^{* *}$ & 0.000 & $0.202^{* *}$ & 0.000 \\
SI7-Versatile & $0.234^{* *}$ & 0.000 & $0.202^{* *}$ & 0.000 \\
SI8-Nice-looking & $0.401^{* *}$ & 0.000 & $0.202^{* *}$ & 0.000 \\
SI9-Hygienic & $0.188^{* *}$ & 0.000 & $0.242^{* *}$ & 0.000 \\
SI10-Replaceable & $-0.113^{* *}$ & 0.009 & 0.013 & 0.760 \\
SI11-Trust & $0.274^{* *}$ & 0.000 & $0.274^{* *}$ & 0.000 \\
SI12-Overall satisfaction & $0.369^{* *}$ & 0.000 & $0.341^{* *}$ & 0.000 \\
SI13-Life-style fitting & $0.330^{* *}$ & 0.000 & $0.229^{* *}$ & 0.000 \\
SI14-Sustainability & $0.151^{* *}$ & 0.001 & $0.125^{* *}$ & 0.004 \\
\hline (**) Significant correlation at 0.01 level. $\left(^{*}\right)$ Significant correlation at 0.05 level.
\end{tabular}

With regard to WK, all the SIs maintained a significant positive correlation with it, except SI3 and SI10. The most correlated impressions were linked to impressions related to achieving a long use of the product, such as SI4 Reliable, SI5 Quality, and SI1 Easy maintenance, and to emotions, such as SI12 Overall satisfaction, SI11 Trust and SI13 Lifestyle fitting. Again, the SIs linked to sustainability and environment maintained weaker correlations (SI14) or no significant correlation (SI3).

Figure 5 shows bar graphs with mean values and 95\% confidence intervals for the means of the assessments of the six design versions, for each SI. The ANOVAs showed statistical differences in all SIs between some of the versions (Table 6). High durability (version 3) and Easy maintenance (version 5), corresponding to strategies for achieving a longer use of the product, were the best rated in SIs about long-life products and product life extension (SI1 Easy maintenance, SI4 Reliable or SI9 Hygienic), as expected, and also regarding trust in the purchase (SI11). The High durability version was also the best rated in SI5 (Quality). The strategies for achieving a varied use of the product, i.e., Adaptable to new functions (version 2) and Flexible design (version 6), were the best rated in 'functional and flexible' SIs, such as Practical (SI6) and Versatility (SI7). The Personalized version (version 4) was assessed as being nicer (SI8), more expensive-looking (SI2) and harder to replace (SI10), but unsustainable (SI14), not very respectful with the environment (SI3), and difficult to maintain (SI1). The Refurbished version (version 1) obtained comparatively lower assessments in aspects such as expensive-looking (SI2), high quality (SI5) or trust in the purchase (SI11), and higher ratings in respect for the environment (SI3) or sustainability (SI14). 


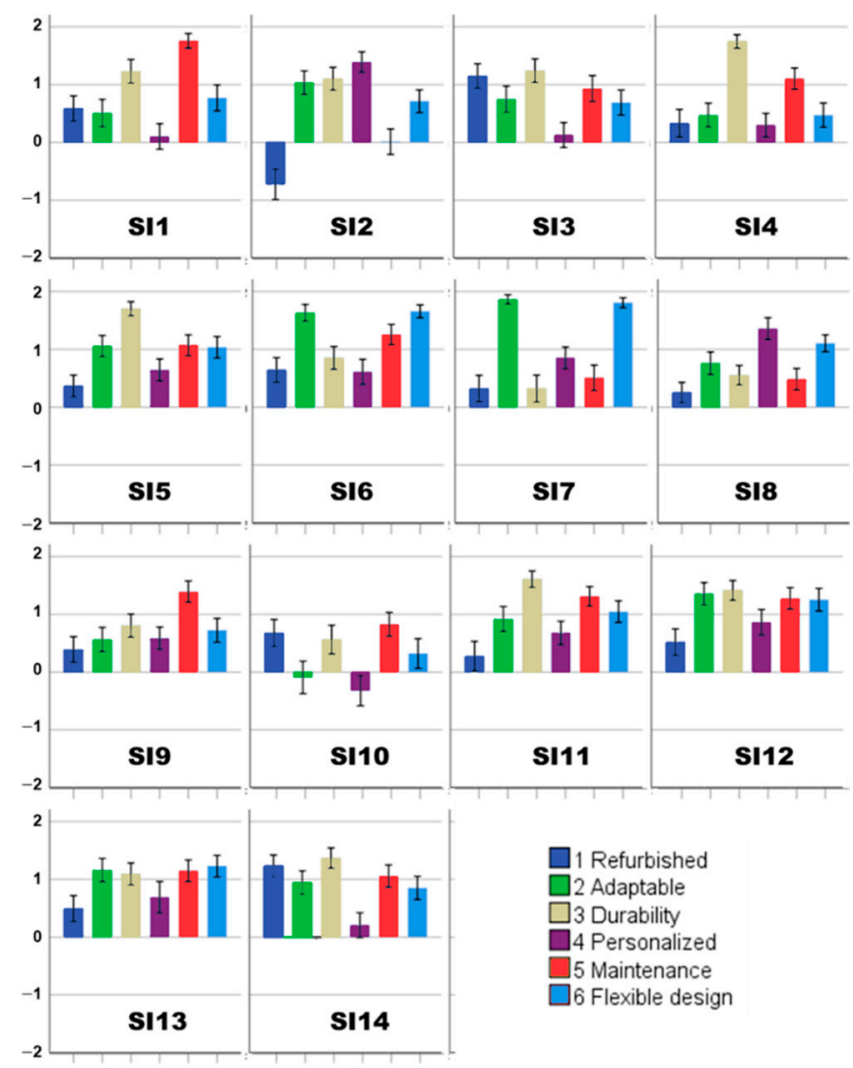

Figure 5. SIs assessments, depending on the sustainability design version. Mean values (bars) and confidence intervals (95\%) for means (lines). Index to SIs in Table 2.

Figure 6 shows mean values and 95\% confidence intervals for the means of the assessments of both BRS for the six design versions. The ANOVAs showed statistical differences for both assessments between version 1 (Refurbished) and all the others. In the case of PA, there was also a significant difference between versions 4 (Personalized) and 5 (Easy maintenance) (Table 6).

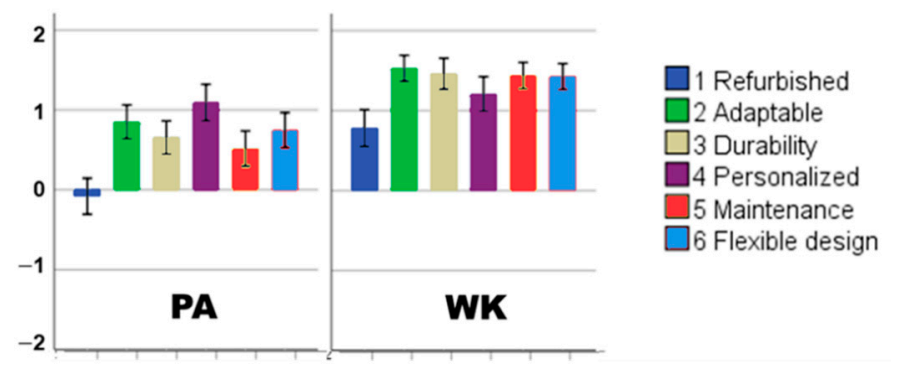

Figure 6. Behavioral response to sustainability design strategies (BRS) assessments, depending on the sustainability design version. Mean values (bars) and confidence intervals (95\%) for means (lines). 
Table 6. Significant differences between design factors (wardrobe versions).

\begin{tabular}{|c|c|c|}
\hline Hypotheses & Differences Based on & Significant Differences ${ }^{1,2}$ \\
\hline $\mathrm{A} 2$ & SI1-Easy maintenance & $1-3 ; 1-4 * ; 1-5 ; 2-3 ; 2-5 ; 3-4 ; 3-5 ; 3-6 * 44-5 ; 4-6 ; 5-6$ \\
\hline $\mathrm{A} 2$ & SI2-Expensive-looking & $1-2 ; 1-3 ; 1-4 ; 1-5 ; 1-6 ; 2-5 ; 3-5 ; 4-5 ; 4-6 ; 5-6$ \\
\hline A2 & SI3-Environmentally respectful & $1-4 ; 1-6 * ; 2-3 * ; 2-4 ; 3-4 ; 3-6 ; 4-5 ; 4-6$ \\
\hline $\mathrm{A} 2$ & SI4-Reliable & $1-3 ; 1-5 ; 2-3 ; 2-5 ; 3-4 ; 3-5 ; 3-6 ; 4-5 ; 5-6$ \\
\hline $\mathrm{A} 2$ & SI5-Quality & $1-2 ; 1-3 ; 1-5 ; 1-6 ; 2-3 ; 2-4 * ; 3-4 ; 3-5 ; 3-6 ; 4-5 * ; 4-6 *$ \\
\hline $\mathrm{A} 2$ & SI6-Practical & $1-2 ; 1-5 ; 1-6 ; 2-3 ; 2-4 ; 2-5 * ; 3-5 * ; 3-6 ; 4-5 ; 4-6 ; 5-6$ \\
\hline A2 & SI7-Versatile & $1-2 ; 1-4 ; 1-6 ; 2-3 ; 2-4 ; 2-5 ; 3-4 ; 3-6 ; 4-6 ; 5-6$ \\
\hline $\mathrm{A} 2$ & SI8-Nice-looking & $1-2 ; 1-4 ; 1-6 ; 2-4 ; 3-4 ; 3-6 ; 4-5 ; 5-6$ \\
\hline $\mathrm{A} 2$ & SI9-Hygienic & $1-5 ; 2-5 ; 3-5 ; 4-5 ; 5-6$ \\
\hline $\mathrm{A} 2$ & SI10_Replaceable & $1-2 ; 1-4 ; 2-3 ; 2-5 ; 3-4 ; 4-5 ; 4-6 ; 5-6$ * \\
\hline $\mathrm{A} 2$ & SI11-Trust & $1-2 ; 1-3 ; 1-5 ; 1-6 ; 2-3 ; 3-4 ; 3-6 ; 4-5$ \\
\hline $\mathrm{A} 2$ & SI12-Overall satisfaction & $1-2 ; 1-3 ; 1-5 ; 1-6 ; 2-4 * ; 3-4$ \\
\hline $\mathrm{A} 2$ & SI13-Lifestyle fitting & $1-2 ; 1-3 ; 1-5 ; 1-6 ; 4-6$ * \\
\hline $\mathrm{A} 2$ & SI14-Sustainability & $1-4 ; 2-3 * ; 2-4 ; 3-4 ; 3-6 ; 4-5 ; 4-6$ \\
\hline $\mathrm{A} 3$ & Attachment & $1-2 ; 1-3 ; 1-4 ; 1-5 ; 1-6 ; 4-5$ \\
\hline A3 & Willingness to keep & $1-2 ; 1-3 ; 1-5 ; 1-6$ \\
\hline
\end{tabular}

\footnotetext{
${ }^{1}$ Significant differences between means at a 0.01 level in all cases, except $\left(^{*}\right)$, which are significant at a 0.05 level.

${ }^{2}$ Wardrobe versions: 1 Refurbished. 2 Adaptable to new functions. 3 High durability. 4 Personalized. 5 Easy maintenance. 6 Flexible design.
}

Table 7 shows descriptive statistics for the SCs. The sustainability concerns most valued by the participants were: $\mathrm{SC7}$, related to keeping some special products; $\mathrm{SC} 3$, referring to personal practicality and responsibility; SC6, which refers to the willingness to maintain and repair personal belongings; and SC1, referring to respect for the environment. The last column shows the frequency (percentage) of values of the dummy variable DSC with high values for each SC.

Table 7. Sustainability concerns. Descriptive statistics.

\begin{tabular}{ccccccc}
\hline Sustainability Concerns & N & Min. & Max. & M & SD & High SC Frequency (\%) \\
\hline SC1-Environmentally & 87 & -1 & 2 & 1.32 & 0.70 & 88.5 \\
$\begin{array}{r}\text { respectful } \\
\text { SC2_Sustainability trusting }\end{array}$ & 87 & -2 & 2 & 0.78 & 0.90 & 66.7 \\
SC3-Practical and responsible & 87 & -1 & 2 & 1.57 & 0.62 & 95.4 \\
SC4-Used to quality & 87 & -2 & 2 & 0.69 & 1.03 & 67.8 \\
SC5-Willing to refurbish & 87 & -2 & 2 & 0.91 & 1.07 & 69.0 \\
SC6-Likes to repair & 86 & -1 & 2 & 1.41 & 0.76 & 86.2 \\
SC7-Product keeper & 87 & -2 & 2 & 1.61 & 0.74 & 92.0 \\
\hline
\end{tabular}

$\mathrm{N}$, sample size; Min., minimum value; Max., maximum value; $\mathrm{M}$, mean; $\mathrm{SD}$, standard deviation.

Figure 7 shows the mean ratings of the SIs, for each DSC. Table 8 shows significant differences found in the ANOVAs with DSC as a factor for each SI. Colored cells are the cases where significant differences were detected. Even though the distribution of cases between the different levels of the DSCs is quite unbalanced for some SCs (especially for DSC3 and DSC7), some differences were nevertheless found. 


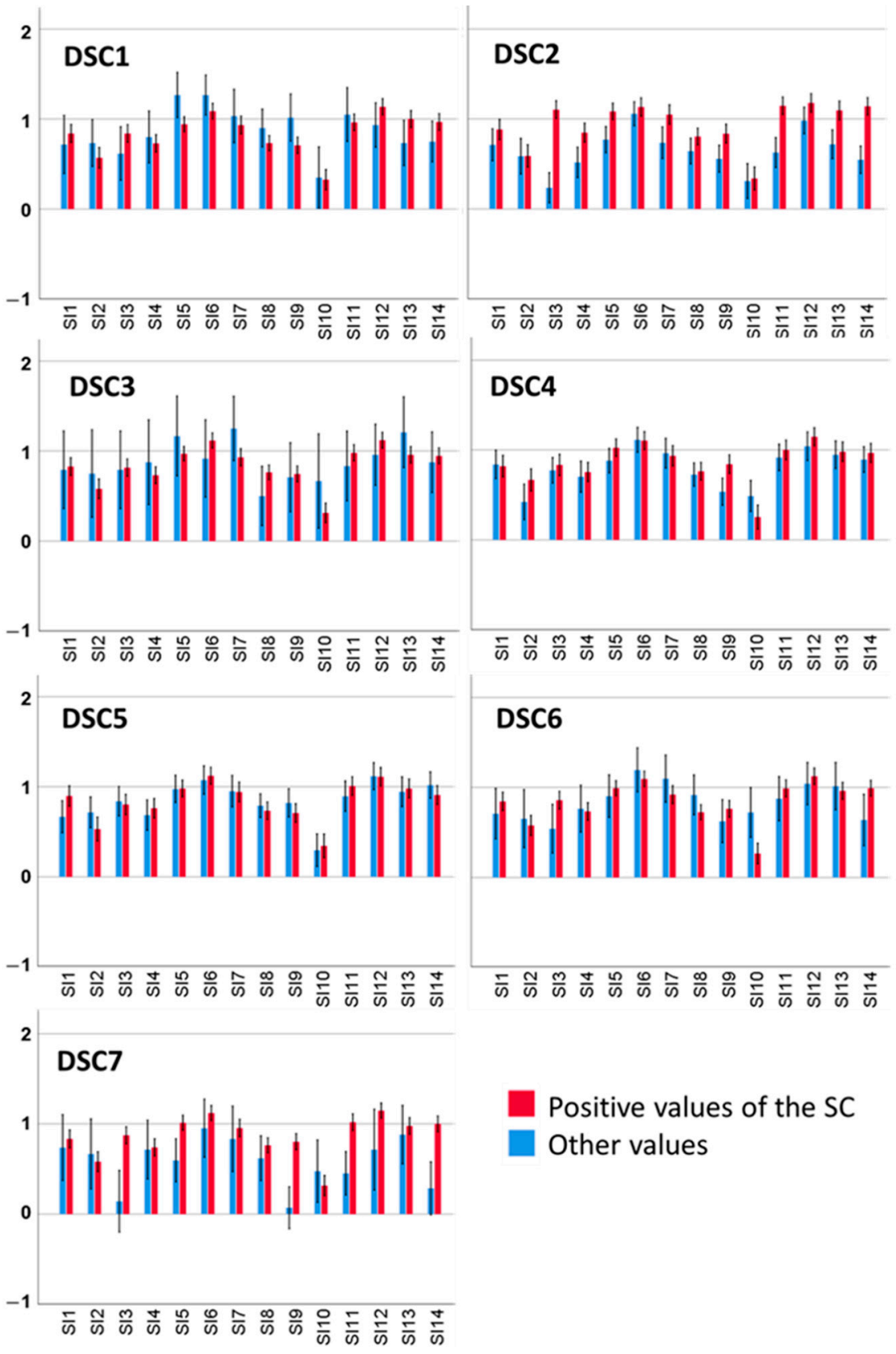

Figure 7. Mean ratings (and 95\% confidence intervals for mean) of the SIs, for each DSC.

Figure 8 shows the values of the full and partial correlation coefficients of the SIs with PA and WK, in order to check the effect of the SCs on this relationship (A5). The greatest change in the coefficient appeared for SI3 (Environmentally friendly), which was not significantly correlated with PA when sustainability criteria were not considered. In addition, some changes were observed in both PA and WK for SI12 (Overall satisfaction) and SI13 (Life-style fitting), and in WK for SI1 (Easy maintenance), SI2 (Expensive-looking) and SI6 (Practical). 
Table 8. Significant differences detected in SI ratings, depending on DSCs.

\begin{tabular}{|c|c|c|c|c|c|c|c|}
\hline & DSC1 & DSC2 & DSC3 & DSC4 & DSC5 & DSC6 & DSC7 \\
\hline SI1-Easy maintenance & & & & & $\mathrm{X}$ & & \\
\hline SI2-Expensive-looking & & & & $x$ & & & \\
\hline $\begin{array}{l}\text { SI3-Environmentally } \\
\text { friendly }\end{array}$ & & $\mathrm{x}$ & & & & $x$ & $x$ \\
\hline SI4-Reliable & & $\mathrm{X}$ & & & & & \\
\hline SI5-Quality & $\mathrm{X}$ & $x$ & & & & & $x$ \\
\hline SI6-Practical & & & & & & & \\
\hline SI7-Versatile & & $x$ & & & & & \\
\hline SI8-Nice-looking & & & & & & & \\
\hline SI9-Hygienic ${ }^{\circ}$ & $\mathrm{X}$ & $x$ & & $x$ & & & $x$ \\
\hline SI10-Replaceable & & & & $x$ & & $x$ & \\
\hline SI11-Trust & & $x$ & & & & & $x$ \\
\hline SI12-Overall satisfaction & & $x$ & & & & & $x$ \\
\hline SI13-Lifestyle fitting & & $x$ & & & & & \\
\hline SI14-Sustainability & & $x$ & & & & $x$ & $x$ \\
\hline
\end{tabular}

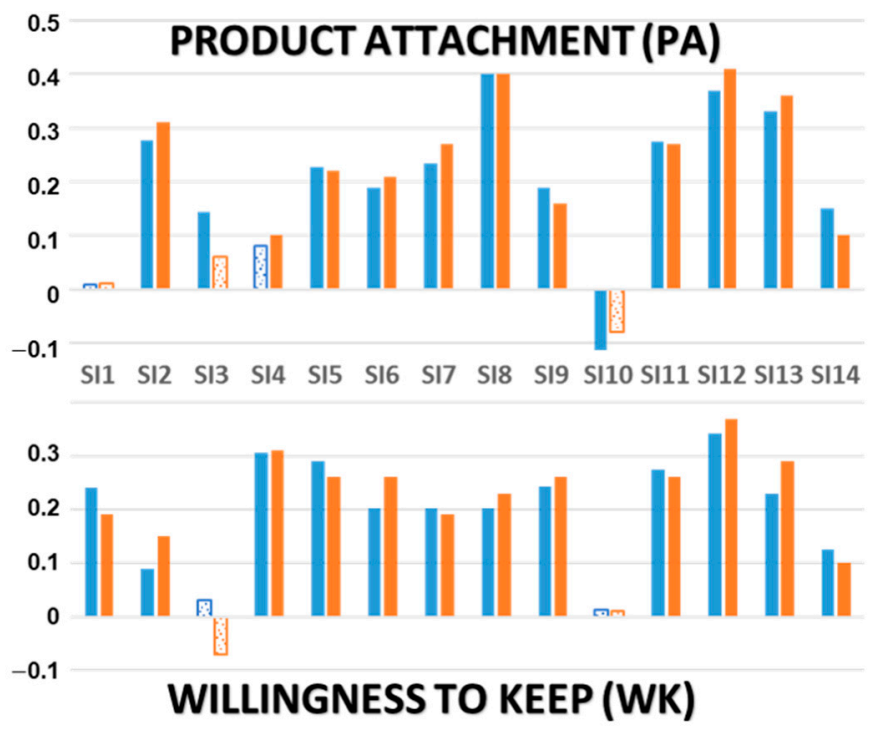

Figure 8. Values of the total and partial correlation coefficients between the SIs and both PA and WK.

Significant correlations are bars with solid shading.

\section{Discussion}

It is known that product design characteristics and personal values and concerns both influence consumers' response [16]. In the field of sustainability, some studies about these influences have already been carried out to favor the desirability of purchasing a product $[16,17,49]$, or to promote sustainable behavior [20,50]. A sustainable paradigm related to product design [24] encourages the extension of product life and its use time. In this sense, affective design can contribute to promote these goals $[9,19,51]$. However, affective design models in the literature consider and distinguish among relationships that occur in the user-product interaction to a greater degree. Thus, within the consumers' response, it is possible to distinguish between the subjective impressions generated (which include both the meanings referring to the product and the emotions elicited in the individual) and the behavioral response; that is, the affect towards it, or the reactions of approaching the product 
or avoiding it [1]. Although the relationship between both components of the response has been demonstrated in the general affective field [7], for the topic of sustainability, this distinction has not been studied in as much detail. Furthermore, this analysis will make it possible to go deeper into the influence of design strategies and personal concerns in the consumers' response.

With this idea in mind, this paper provides a novelty, as it proposes a comprehensive model about consumer-product interactions while considering the relationships produced between the subjective impressions generated and the behavioral response from a sustainability point of view. The influence of factors from the designers' domain (i.e., strategies for sustainable design) and from the consumers' domain (sustainability concerns) on the consumers' response are also considered.

Previous works have not delved in such detail into the study of the affective relationships between these factors. Some models in the literature have analyzed the mediation effect of affect between cognition and behavior, focused on purchasing intention [51], while in this work, the study of behavior has focused on the post-purchase phase, and is referred to factors that favor a long product life, distinguishing between attachment and willingness to keep.

Specifically, six versions of a wardrobe were defined to reflect different sustainability design strategies [26,27], which were classified according to their aim [9,41]: achieving product utility for a longer time, enhancing product usability over time and targeting aspirational desires. Seven concerns, mainly personal values and criteria related to sustainability, were also considered. Consumers' response was represented by 14 subjective impressions related to product long-life, functionality, aesthetics and environment, and by two product-related behavioral responses to the sustainability strategies (product attachment and willingness to keep).

Figure 9 summarizes the relationships obtained between the subjective impressions and the behavioral responses (relationship A1 of the model). The intensity of the shaded cells in the third and fourth columns represents the strength of the correlation. Additionally, for each design strategy, the highest and lowest ratings for PA, WK and SIs have been indicated with positive or negative signs, respectively (relations $\mathrm{A} 3$ and $\mathrm{A} 2$ ).

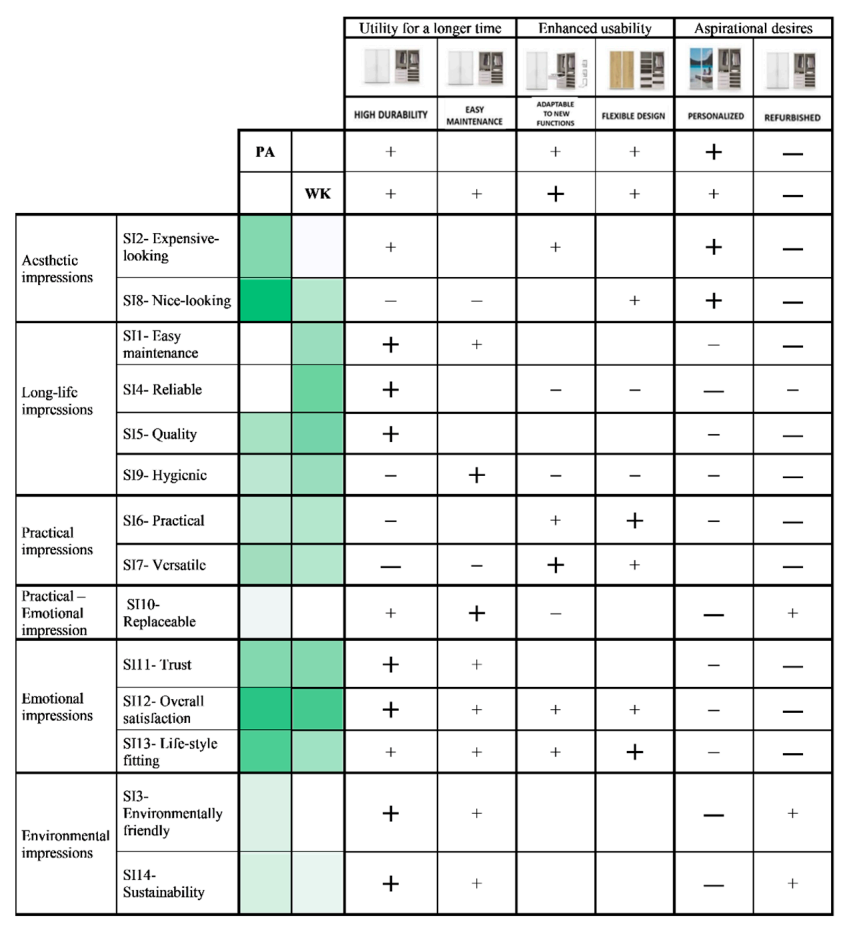

Figure 9. Summary of the relationships. Third and fourth columns: shading intensity indicates the strength of the correlation. Columns with design versions: for each file (SI), bold large signs indicate the design versions with the highest $(+)$ and lowest $(-)$ mean rating; small signs indicate the versions without any significant differences from the highest $(+)$ or lowest $(-)$ ones. 
There is a strong correlation between the subjective impressions and consumers' behavioral responses (relationship A1 in the model in Figure 1): 11 (out of 14) SIs were significantly correlated with PA, and 12 in the case of WK (Figure 9, shaded columns). Aesthetic impressions are the most related to PA, in line with Schifferstein and Zwartkruis-Pelgrim [30], who suggested that product enjoyment is a driver of attachment, which contains the aesthetic pleasure derived from a beautiful appearance, among other aspects. Furthermore, long-life impressions are more correlated with WK and emotional impressions are strongly correlated with both behavioral responses. Practical impressions are also (although not so strongly) correlated with both behavioral responses. Conversely, environmental impressions have obtained low or non-existent correlations with the BRS. This raises a reflection about the idea, mentioned in the introduction, that consumers apply criteria that go beyond functionality or aesthetics and are more closely related to ensuring a lower impact on the environment, which does not seem to be supported by these results. In contrast, our results are in line with Luchs et al. [15], who claimed that only beyond a certain threshold of functional performance achieved are other aspects more closely related to aspirational desires valued, the aesthetic one having a high value in the final choice.

Sustainability design strategies influence consumers' behavioral responses, through their relationship with the subjective impressions (relationships A3 and A2). The versions with strategies related to achieving product utility for a longer time (High durability and Easy maintenance) are positively assessed on most impressions, mainly on emotional and long-life ones, which in turn are more related to WK, leading to the highest assessments in WK. These strategies, oriented toward longer performance, are better assessed than those seeking aspirational desires (Personalized and Refurbished). This agrees with the results of Luchs et al. [15], who found that consumers prefer a product perceived as superior in functional performance rather than superior in sustainability characteristics.

The versions with strategies for enhanced product usability (Adaptive to new functions and Flexible design) are also related to $\mathrm{WK}$, and at the same time they maintain a higher relation to PA. These versions have a particular influence on the assessment of the practical impressions, and also on the emotional ones, which in turn maintain strong correlations with both PA and WK. Our results agree with those of Hata et al. [52], who concluded that modular design increases the chance of reuse. If a product is based on a modular design, replacing some parts or even cleaning it will be easier, which could lead consumers to keep it for longer.

The versions corresponding to strategies aimed at aspirational desires (Personalized and Refurbished) show quite different results. The personalized version has the highest influence on aesthetic impressions, which are highly related to PA. In fact, this version is the best assessed for PA. However, although the aesthetic characteristics (especially SI8, Nice-looking, strongly correlated to PA) have managed to increase the perception of PA, the perception of the rest of the impressions has low assessments compared to other versions. Results for emotional impressions stand out: the versions for utility and usability have obtained better assessments on trust, satisfaction and lifestyle-fitting than the personalized version, which could be related to the high functional load of the product chosen in the study. Further research would be needed in order to confirm that the relationship between emotions and certain product meanings varies depending on the type of product, since this result does not correspond to the idea that personalization is a design factor that stimulates emotional bonding with the product [53], at least for the product used in this application (wardrobes). However, despite the strong correlation of emotional impressions with PA, the Personalized version obtained the best assessment in PA, above that of the versions for utility and usability. This is an interesting result, as it highlights the idea that perceived positive aesthetic qualities influence the acceptance of a design, or the perception of other product characteristics, such as usability or performance, in accordance with other works $[10,54,55]$.

The Refurbished version was the one with the worst assessment on both PA and WK, and on most subjective impressions. It only presents positive ratings on the environmental and the replaceable impressions. Therefore, even though wardrobes have been previously chosen as a product category that would potentially accept refurbishment [56], other strategies are better accepted by consumers to 
increase PA and WK. Mugge et al. [40] verified that, although participants showed a positive attitude towards refurbished smartphones, most of the highest scoring incentives underlying the purchase were product-related. Therefore, perceived environmental benefits should be studied depending on the customers and also on the product.

The results described up to this point indicate that the consumers' response can be influenced by factors from the designers' domain, through the design strategy, as they affect subjective impressions, which are related to the behavioral response. Long-life impressions are more linked to WK, while aesthetical impressions are more related to PA, and practical and especially emotional impressions are linked to both WK and PA. From a sustainable approach, managers and designers should consider that in order to achieve a greater consumer willingness to take care of the product and give it a long useful life, the most appropriate strategies are those related to utility and usability. However, the highest levels in both behavioral responses (PA and WK) are not achieved at the same time; PA increases as the product is provided with possibilities allowing it to change, such as flexibility and adaptability, reaching its maximum value for product personalization. As designers obviously desire a product response that achieves a high degree of attachment, it will be necessary to consider other characteristics, in addition to those related to utility and usability. Thus, although the consideration of functional characteristics is an adequate strategy to achieve long-life products, incorporating modular, versatile and aesthetical characteristics into sustainable products can help to achieve greater consumer engagement. This engagement is even more relevant, considering that the environmental impressions maintain weaker or inexistent correlations with PA and WK. In fact, the Refurbished version, with high assessments on the environmental impressions, had poor assessments in almost all the other impressions.

However, it is worth noting the effect of sustainability concerns on consumers' subjective impressions and on their relationship with the behavioral responses (relationships A4 and A5 in the model in Figure 1). Thus, for example, consumers who define themselves as 'used to quality' rated the impressions Expensive-looking and Hygienic significantly higher than the rest, while those who define themselves as environmentally respectful rated these impressions with significantly lower ratings than those who are not especially concerned about the environment. Those who said they like to repair rated the impressions Environmentally friendly and Sustainability significantly higher than the rest. Furthermore, the previously mentioned correlation between the impression Environmentally friendly and PA disappears if the effect of sustainability concerns is not considered. Designers should therefore also consider whether the designed product is addressed to a particularly aware type of consumers, in order to weigh up the functional, versatile and aesthetic characteristics that should shape the product $[2,7]$.

Although principles of affective human-factors design have previously been applied to sustainability $[20,49,50]$, the distinctions made in this work between types of consumer responses (subjective impressions and behavior), between behavioral responses (product attachment and willingness to keep it) and their relationships with consumers' concerns have made it possible to offer managers and designers interesting results regarding how to generate sustainable responses in consumers. Therefore, by knowing what factors influence certain types of consumers to have a greater attachment and willingness to keep, designers can create the most appropriate products, based on the customer profile and their concerns.

The influence of any design strategy on the consumers' behavior (relationship A3 in the Introduction section) should be analyzed in two phases. One phase should consider their effect on the subjective impressions elicited (relationship A2 in the model proposed in Figure 1) and the other phase should consider the relation (A1 in the model) of these subjective impressions with the behavioral response (in this work measured as attachment and willingness to keep the product). Our results are an example illustrating the importance of distinguishing between subjective impressions elicited and behavioral response: in order to reduce the environmental impact of a product by means of a high attachment to it, the subjective impressions that should be generated are not those 
related to the environmental aspect, as could be expected, but rather the emotional, aesthetical and practical impressions.

The relationship between subjective impressions and behavioral response (A1 in our model) is expected to be more stable than its relationship with the design strategies (A2). The elicitation of subjective impressions from a product design could change over time, due to factors such as fashion or technology. For example, a black product could be perceived as modern or classic, depending on the current fashion, whereas individuals' preference for products that are modern or classic is usually more stable over time. Of course, the personal situation of each consumer also exerts an influence, and so concerns should also be considered (relationships A4 and A5 in our model).

It is also worth noting the distinction made between different behavioral responses, which, to our knowledge, has not previously been studied in the literature. Although the results obtained show that most subjective impressions are related to both product attachment and willingness to keep, some cases in which only one of the behavioral responses was related have been identified. This result provides encouragement to keep on studying the types of behavioral responses that can be favored by meanings and emotions generated by product design.

The study has been applied to wardrobes, and it is expected that specific results of the study (such as how a specific strategy as refurbishment affects the behavioral response, or how a specific concern influences the consumers' response) are also applicable to types of products that can trigger similar affective relationships (such as furniture, lamps, domestic appliances), as there is evidence from previous works that the acceptance of some strategies depends on the type of product [56]. However, other types of products could present other specific relationships. For example, the fact that the utility and usability versions have a more positive influence on the emotional impressions than those of the personalized one could be a specific result for this type of products that could not appear in products more subjected to fashion changes such as glasses, for instance. Further work should study sustainability strategies for other types of products, or even services, as, for instance, hotels or restaurants, offering sustainable services.

Some limitations in the study must be highlighted. Participants self-reported their sustainability concerns and assessed SIs, PA and WK for the six versions of a wardrobe, but these assessments could differ from real concerns and behaviors. The study considers product attachment as a potential bond that a consumer could have with a product. The authors are aware that emotional attachment includes a previous experience with objects. However, in this research consumers should imagine a hypothetical situation and interaction with a wardrobe. Moreover, perceptions are focused on the first interaction between the individual and the wardrobe, and emotional reactions could change over time [57]. Replicating the experience with another specific sample balanced on each SC level would be interesting to validate results, as this was not considered in this work. Finally, socio-economic variables could be analyzed in order to examine their influence on affective design principles for improving product attachment and willingness to keep.

\section{Conclusions}

The principles of affective design are important considerations in sustainability. Their application is useful in promoting long-term involvement with products. In this paper, a conceptual model has been proposed that applies principles of affective design with the aim of exploring the generation of consumer responses in greater depth, based on the sustainability strategies adopted in product design.

Results have shown that sustainability design strategies influence consumers' behavioral responses, through their relationship with the subjective impressions elicited. The distinction between the subjective impressions and the behavioral responses within consumers' response has made it possible to differentiate between several types of relationships. On the one hand, various types of subjective impressions have a different influence on product attachment and willingness to keep, which have been adopted as being representative of behavioral responses to the sustainable design strategies. On the other hand, the influence of different design strategies on consumers' responses (subjective impressions, 
product attachment, and willingness to keep) has been analyzed. The proposed conceptual model also considers the influence of personal concerns on consumers' response.

It is hoped that the results presented in this work can be applied by managers and designers in order to promote a sustainable behavior and help them select the most suitable design strategies, according to the concerns of the target consumer. Considering functional characteristics is an adequate strategy to achieve long-life products. Meanwhile, incorporating versatile and aesthetical characteristics into sustainable products can help to achieve greater consumer engagement. Furthermore, due to the role of sustainability concerns, special consideration should be given if the product is addressed to a particularly aware type of consumers. The influence of a design strategy on the consumers' behavior should be analyzed in two phases: the effect on the subjective impressions elicited, and the relationship between the subjective impressions and the behavioral response. Designers should also consider that the relationship between subjective impressions and behavioral response is expected to be more stable in time than its relationship with the design strategies.

Although this affective model can be applied to any type or product, the specific results of this study are applicable to similar types of products, such as furniture, lamps or domestic appliances. Further studies should be carried out to study the specific responses elicited and the relationships between them, while considering sustainability strategies for other types of products or even services.

Author Contributions: Conceptualization, methodology, formal analysis, writing-review and editing, M.-J.A. and M.V.; writing-original draft preparation, funding acquisition, M.-J.A. All authors have read and agreed to the published version of the manuscript.

Funding: This research was funded by the Universitat Jaume I, grant number 16I342.01/1.

Acknowledgments: We are grateful to Mónica Toribio for her help in the preparation and development of the study and in data collection.

Conflicts of Interest: The authors declare no conflict of interest. The funders had no role in the design of the study; in the collection, analyses or interpretation of data; in the writing of the manuscript or in the decision to publish the results.

\section{References}

1. Crilly, N.; Moultrie, J.; Clarkson, P.J. Seeing things: Consumer response to the visual domain in product design. Des. Stud. 2004, 25, 547-577. [CrossRef]

2. Desmet, P. Designing Emotions. Ph.D. Thesis, Delft University of technology, Delft, The Netherlands, 2002.

3. Kumar, M.; Noble, C.H. Beyond form and function: Why do consumers value product design. J. Bus. Res. 2016, 69, 613-620. [CrossRef]

4. Desmet, P.; Hekkert, P. Framework of Product Experience. Int. J. Des. 2007, 1, 57-66. [CrossRef]

5. Chitturı, R. Emotions by Design: A Consumer Perspective. Int. J. Des. 2009, 3, 7-17. [CrossRef]

6. Fenech, O.C.; Borg, J.C. Exploiting Emotions for Successful Product Design. In Proceedings of the 16th International Conference on Engineering Design, Paris, France, 28-31 August 2007; pp. 1-12.

7. Agost, M.J.; Vergara, M. Relationship between Meanings, Emotions, Product Preferences and Personal Values. Application to Ceramic Tile Floorings. Appl. Ergon. 2014, 45, 1076-1086. [CrossRef]

8. Chapman, J. Emotionally Durable Design: Objects, Experiences \& Empathy, 1st ed.; Earthscan: London, UK, 2005.

9. Carey, M.; White, E.J.; McMahon, M.; O'Sullivan, L.O. Using personas to exploit environmental attitudes and behaviour in sustainable product design. Appl. Ergon. 2019, 78, 97-109. [CrossRef]

10. Helander, M.G.; Khalid, H.M. Affective and Pleasurable Design. In Handbook on Human Factors and Ergonomics, 3rd ed.; Salvendy, G., Ed.; John Wiley \& Sons, Inc.: Hoboken, NJ, USA, 2006; pp. 543-572.

11. Khalid, H.M. Embracing Diversity in User Needs for Affective Design. Appl. Ergon. 2006, 37, 409-418. [CrossRef]

12. Boztepe, A. Green Marketing and Its Impact on Consumer Buying Behavior. Eur. J. Econ. Political Stud. 2012, $5,5-21$.

13. Finisterra Do Paço, A.M.; Barata Raposo, M.L.; Filho, W.L. Identifying the Green Consumer: A Segmentation Study. J. Target. Meas. Anal. Mark. 2009, 17, 17-25. [CrossRef] 
14. Stewart, B.; Gilg, A.; Shaw, G. Citizens, Consumers and Sustainability: (Re) Framing Environmental Practice in an Age of Climate Change. Glob. Environ. Chang. 2011, 21, 1224-1233. [CrossRef]

15. Luchs, M.G.; Brower, J.; Chitturi, R. Product Choice and the Importance of Aesthetic Design given the Emotion-Laden Trade-off between Sustainability and Functional Performance. J. Prod. Innov. Manag. 2012, 29, 903-916. [CrossRef]

16. Gutierrez, A.M.J.; Shun Fung Chiu, A.; Seva, R. A Proposed Framework on the Affective Design of Eco-Product Labels. Sustainability 2020, 12, 3234. [CrossRef]

17. Steenis, N.D.; Lans van der, I.A.; Herpen van, E.; van Trijp, H.C.M. Effects of sustainable design strategies on consumer preferences for redesigned packaging. J. Clean. Prod. 2018, 205, 854-865. [CrossRef]

18. Boz, Z.; Korhonen, V.; Sand, C.K. Consumer considerations for the implementation of sustainable packaging: A review. Sustainability 2020, 12, 2192. [CrossRef]

19. Thatcher, A. Affect in designing for sustainability in human factors and ergonomics. Int. J. Hum. Factors Ergon. 2012, 1, 127-147. [CrossRef]

20. Seva, R.R. Product-behavior targeting: Affective design method for sustainability. In Proceedings of the International MultiConference of Engineers and Computer Scientists 2019, IMECS, Hong Kong, China, 13-15 March 2019.

21. Lilley, D. Design for Sustainable Behaviour: Strategies and Perceptions. Des. Stud. 2009, 30, 704-720. [CrossRef]

22. Lockton, D.; Harrison, D.; Stanton, N. Making the User More Efficient: Design for Sustainable Behaviour. Int. J. Sustain. Eng. 2008, 3-8. [CrossRef]

23. Kakee, S.; Bakker, C.; Quist, J. Designing Change by Living Change. Des. Stud. 2012, 33, 279-297. [CrossRef]

24. Potocnik, J. Towards a Circular Economy_Economic and Business Rationale for an Accelerated Transition; The Ellen MacArthur Foundation: Cowes, UK, 2012; Available online: https://www.ellenmacarthurfoundation.org/ assets/downloads/publications/Ellen-MacArthur-Foundation-Towards-the-Circular-Economy-vol.1.pdf (accessed on 9 September 2019).

25. Goworek, H.; Oxborrow, L.; Claxton, S.; McLaren, A.; Cooper, T.; Hill, H. Managing sustainability in the fashion business: Challenges in product development for clothing longevity in the UK. J. Bus. Res. 2020, 117, 629-641. [CrossRef]

26. Nes, N.v.; Cramer, J. Influencing Product Lifetime through Product Design. Bus. Strategy Environ. 2005, 14, 286-299. [CrossRef]

27. Bocken, N.M.P.; De Pauw, I.; Bakker, C.; Van Der Grinten, B. Product Design and Business Model Strategies for a Circular Economy. J. Ind. Prod. Eng. 2016, 33, 308-320. [CrossRef]

28. Carter, I. Human Behavior in the Social Environment: A Social Systems Approach, 6th ed.; Rutgers University; Transaction Publishers: Piscataway, NJ, USA, 2011; pp. 1-306. ISBN 978-1-4128-4433-8.

29. Noonan, J.D.; Murphy-White, S.; Foord, G. Walking the Walk on Environmental Assurance: A Case Study of Vegetable Growers in Western Australia. In Proceedings of the 3rd International Symposium on Improving the Performance of Supply Chains in the Transitional Economies, Kuala Lumpur, Malaysia, 4-8 July 2010; Volume 895.

30. Schifferstein, H.N.J.; Zwartkruis-Pelgrim, E.P.H. Consumer-Product Attachment: Measurement and Design Implications. Int. J. Des. 2008, 2, 1-13.

31. Hemel, C.G.v.; Brezet, J.C. Ecodesign; A Promising Approach to Sustainable Production and Consumption; United Nations Environment Programme, Industry and Environment, Cleaner Production: Paris, France, 1997.

32. Qifang, B.; Burnell, E.; Hughes, A.M.; Yang, M.C. Investigating User Emotional Responses to Eco-Feedback Designs. J. Mech. Des. Trans. Asme 2019, 141,1-14. [CrossRef]

33. She, J.; Macdonald, E.F. Exploring the Effects of a Product's Sustainability Triggers on Pro-Environmental Decision-Making. J. Mech. Des. Trans. Asme 2018, 140, 1-13. [CrossRef]

34. Jiménez-Parra, B.; Rubio, S.; Vicente-Molina, M.A. Key Drivers in the Behavior of Potential Consumers of Remanufactured Products: A Study on Laptops in Spain. J. Clean. Prod. 2014, 85, 488-496. [CrossRef]

35. Weelden, E.v.; Mugge, R.; Bakker, C. Paving the way towards circular consumption: Exploring consumer acceptance of refurbished mobile phones in the Dutch market. J. Clean. Prod. 2016, 113, 743-754. [CrossRef]

36. Maniatis, P. Investigating Factors Influencing Consumer Decision-Making While Choosing Green Products. J. Clean. Prod. 2016, 132, 215-228. [CrossRef] 
37. Ackermann, L.; Mugge, R.; Schoormans, J. Consumers' Attitudes towards Product Care. An Exploratory Study of Motivators, Ability Factors and Triggers. In Proceedings of the PLATE Conference, Delft University of Technology, Delft, The Netherlands, 8-10 November 2017.

38. Bouchard, C.; Brissaud, D.; Aoussat, A. User Kansei Modeling and Eco-Design. Asian Int. J. Sci. Technol. Prod. Manuf. Eng. 2010, 3, 1-6.

39. Sanya, C.; Yahng, L. Willingness-To-Pay for Sustainable Beer. PLoS ONE 2018, 13, e0204917. [CrossRef]

40. Mugge, R.; Jockin, B.; Bocken, N. How to Sell Refurbished Smartphones? An Investigation of Different Customer Groups and Appropriate Incentives. J. Clean. Prod. 2017, 147, 284-296. [CrossRef]

41. Jordan, P.W. Designing Pleasurable Products: An Introduction to the New Human Factors; CRC Press: London, UK, 2002.

42. Fenix for Interiors. Available online: http://www.fenixforinteriors.com/ (accessed on 10 July 2020).

43. Lagrama. Available online: http://www.lagrama.es (accessed on 10 July 2020).

44. Muebles Lluesma. Available online: http://www.muebleslluesma.com (accessed on 10 July 2020).

45. Thompson, D.W.; Anderson, R.C.; Hansen, E.N.; Kahle, L.R. Green segmentation and environmental certification: Insights from forest products. Bus. Strategy Environ. 2010, 19, 319-334. [CrossRef]

46. Carvalho, B.; Salgueiro, M.F.; Rita, P. Consumer sustainability consciousness: A five dimensional construct. Ecol. Indic. 2015, 58, 402-410. [CrossRef]

47. Mohd Suki, N. Consumer environmental concern and green product purchase in Malaysia: Structural effects of consumption values. J. Clean. Prod. 2016, 132, 204-214. [CrossRef]

48. Nguyen, N.; Lobo, A.; Greenland, S. Pro-environmental purchase behaviour: The role of consumers' biospheric values. J. Retail. Consum. Serv. 2016, 33, 98-108. [CrossRef]

49. Gutierrez, A.M.J.; Seva, R.R. Affective responses in the purchase of consumer eco products. Bus. Econ. Rev. 2016, 25, 129-146.

50. Bhamra, T.; Lilley, D.; Tang, T. Design for sustainable behavior: Using products to change consumer behavior. Des. J. 2011, 14, 427-445.

51. Haile, T.T.; Kang, M. Mobile Augmented Reality in Electronic Commerce: Investigating User Perception and Purchase Intent amongst Educated Young Adults. Sustainability 2020, 12, 9185. [CrossRef]

52. Hata, T.; Kato, S.; Kimura, F. Design of Product Modularity for Life Cycle Management. In Proceedings of the Second International Symposium on Environmentally Conscious Design and Inverse Manufacturing, Tokyo, Japan, 11-15 December 2001; pp. 93-96. [CrossRef]

53. Mugge, R.; Schoormans, J.P.L.; Schifferstein, H.N.J. Emotional Bonding with Personalised Products. J. Eng. Des. 2009, 20, 467-476. [CrossRef]

54. Norman, D.A. Emotional Design: Why We Love (or Hate) Everyday Things; Basic Books: New York, NY, USA, 2004.

55. Sauer, J.; Sonderegger, A. The influence of prototype fidelity and aesthetics of design in usability tests: Effects on user behaviour, subjective evaluation and emotion. Appl. Ergon. 2009, 40, 670-677. [CrossRef]

56. Mugge, R.; Safari, I.; Balkenende, R. Is There a Market for Refurbished Toothbrushes? An Exploratory Study on Consumers' Acceptance of Refurbishment for Different Product Categories. In Proceedings of the Product Lifetimes and the Environment 2017 Conference, Delft, The Netherlands, 8-10 November 2017; pp. $293-302$.

57. Karapanos, E.; Zimmerman, J.; Forlizzi, J.; Martens, J.-B. 2009 User Experience over Time: An Initial Framework. In Proceedings of the 27th Annual CHI Conference on Human Factors in Computing Systems, Boston, MA, USA, 4-9 April 2009; Greenberg, S., Hudson, S.E., Hinkley, K., Ringelorris, M., Olsen, D.R., Eds.; Volume 1-4, pp. 729-738.

Publisher's Note: MDPI stays neutral with regard to jurisdictional claims in published maps and institutional affiliations.

(C) 2020 by the authors. Licensee MDPI, Basel, Switzerland. This article is an open access article distributed under the terms and conditions of the Creative Commons Attribution (CC BY) license (http://creativecommons.org/licenses/by/4.0/). 